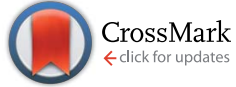

Cite this: RSC Adv., 2017, 7, 13957

Received 7th December 2016 Accepted 10th February 2017

DOI: $10.1039 / c 6 r a 27883 c$

rsc.li/rsc-advances

\section{Herbicide exposure induces apoptosis, inflammation, immune modulation and suppression of cell survival mechanism in murine model}

\author{
Aaveri Sengupta, Krishnendu Manna, Siddhartha Datta, Ujjal Das, Sushobhan Biswas, \\ Nilkanta Chakrabarti and Sanjit Dey*
}

The lymphatic organ, the spleen, is of immense immunological importance as it is the largest blood filter in the mammalian system. The objective of the current study is to explore the detrimental cellular and subcellular effects in the spleen, mediated by the widely used herbicide, paraquat (PQ). PQ is an uncoupling agent for the electron transport chain complex in the mitochondria, which promulgates serious alterations in the intracellular oxidative microenvironment. This leads to the activation of a cascade of sub cellular events leading to cell death. Since $P Q$-induced oxidative damage in the spleen is not well explored, we planned to develop a PQ toxicity model in rodents, addressing its negative effects in the highest molecular terms. The toxicity markers were evaluated in terms of oxidative stress, cellular apoptosis, inflammation and splenomegaly in Swiss albino mice after treatment with PQ. The increase in thiobarbituric acid reactive substances (TBARS), tissue nitrite formation, intracellular reactive oxygen species (iROS) production, depletion of the activities of catalase (CAT), glutathione (GSH), superoxide dismutase (SOD) and the reduction in mitochondrial inner trans membrane potential (MMP) were significant in the $P Q$ treated group compared to the control. A pronounced inhibition of cell proliferative response and increased p53, Bax expression, caspase 3 activities and decreased Bcl-2 were also associated with $\mathrm{PQ}$-induced apoptosis. Moreover, a pro-inflammatory response was apparent in the $\mathrm{PQ}$ treated group as indicated by elevated levels of pro-inflammatory markers (TNF- $\alpha$, IL- 6 and COX-2). Thus, this is perhaps the first mechanistic report showing how a herbicide induces the oxidative stress responsible for immunomodulation, apoptosis, as well as splenomegaly in the murine system.

\section{Introduction}

As the largest peripheral lymphoid tissue of the body, the spleen performs a crucial role in immune function with the help of the lymphoid macrophages, T and B lymphocytes, which kill pathogens and produce antibodies. The spleen filters the blood, acts as a store house for Red Blood Cells (RBC) and scavenges the dead, damaged RBC, recycling the iron and protein components. ${ }^{1}$

Paraquat (PQ), a toxic, pro-oxidant herbicide, causes detrimental biological effects through oxidative stress injury and mitochondrial dysfunction. Upon entering the cell, the redox cycling of $\mathrm{PQ}^{2+}$ is initiated by mitochondrial and cytosolic enzymes like NADPH oxidase, NADPH cytochrome $\mathrm{C}$ reductase and nitric-oxide synthase. ${ }^{2,3}$ On the other hand, it is reduced to an unstable free radical and then reoxidized to form the cation,

Department of Physiology, DST-PURSE \& UGC-CPEPA Supported Department, Centre for Research in Nanoscience \& Nanotechnology (CRNN), University of Calcutta, 92, A.P.C Road, Kolkata - 700009, West Bengal, India. E-mail: sanjitdey@gmail.com; Fax: +91-33-23519755; Tel: +91-9830211512 which ultimately produces a superoxide anion., ${ }^{4,5}$ PQ induces oxidative stress by generating excessive intracellular reactive oxygen species (iROS) and alters mitochondrial function leading to apoptosis; therefore, apoptosis of the spleen cells proves to be fatal. ${ }^{6,7}$ Different in vivo and in vitro studies have revealed that apoptosis in splenocytes leads to immunosuppression in rodents. ${ }^{\mathbf{2}}$

The relationship between exposure to different doses of PQ and Parkinson's disease development is well documented., ${ }^{\mathbf{9 , 1 0}}$ Apart from brain dysfunction, PQ can induce liver damage and failure of the lung, heart and kidney functions within several days to several weeks. As a potent ROS generator, PQ causes cellular damage in different organs by either the process of immune suppression, inflammation, apoptosis or necrosis. Moreover, shifting the redox balance results in the impairment of intracellular ionic homeostasis, which affects DNA, protein or lipid. ${ }^{9}$ ROS result in increased lipid peroxidation (LPO) and depletion of ROS scavenging enzymes such as SOD, CAT and GPx (glutathione peroxidase). ${ }^{\mathbf{1 1 2}}$ An animal study in rats and a cell culture study with normal human lung epithelial cells have 
demonstrated that post-treatment with $\mathrm{N}$-acetyl-L-cysteine (NAC) in paraquat intoxication can significantly increase the survival rate and lower the paraquat induced oxidative stress and inflammatory response, in which the cellular glutathione level plays an essential role in the antioxidant defence mechanism. ${ }^{13}$ Another experimental study confirmed that Croton cajucara leaf extract shows free radical scavenging activity, and ameliorates oxidative stress by PQ, suggesting its beneficial use as a potent source of antioxidant substances from natural origin. ${ }^{\mathbf{1 4}}$

Andrographolide, a major bioactive chemical of the plant Andrographis paniculata and its derivatives, has antioxidant activities in vivo and in vitro and reduces the free radical damage by PQ. ${ }^{15}$

Thus, our hypothesis is that PQ may be related to the activation of some molecular events leading to apoptotic cell death.

We have studied two crucial elements of apoptosis from the Bcl-2 family and caspase enzymes that are involved in the process of apoptosis in the spleen cells. The Bcl-2 family of proteins are a set of cytosolic elements that function in opposite directions: $\mathrm{Bcl}-2$ and $\mathrm{Bcl}-\mathrm{x}_{\mathrm{L}}$ act to inhibit apoptosis, whereas Bax counteracts this effect. On the other hand, caspase enzymes work in a cascade manner and caspase- 3 is one of the most important members of this family, which plays an effective role in apoptotic pathways in different cells. ${ }^{16}$ We postulate that apoptosis is also associated with change in MMP. Previous studies confirm that a decline in MMP manifests oxidative stress and eventually leads to cell death. ${ }^{17}$ It is also reported that PQ caused S-phase arrest of the cell cycle in rat liver and lung cells in vivo and it affects the DNA. ${ }^{18}$

Another report reveals that some signature molecules of acute PQ poisoning like the calcium signaling-related proteins, calcium binding protein 1 (CaBP1), FK506 binding protein 4 (FKBP4), S100A6 and secreted protein acidic and rich in cysteine (Sparc, also known as osteonectin) are upregulated by PQ treatment and decreased by acai berry treatment. ${ }^{19}$ Another study with PC12 cells validates that the extract of Bacopa monnieri can be used as a potent therapeutic agent in the prevention of PD by modulating oxidative stress and redox signalling pathways induced by PQ or diquat. ${ }^{20}$

In the present study, we investigate the effects of oxidative stress caused by PQ on the splenocytes of adult male Swiss albino mice. We also focus on the concomitant changes in the levels of oxidative stress indicators (iROS, LPO, SOD, CAT, GSH and tissue nitrite formation), immunomodulatory molecules (IL-6, TNF- $\alpha$, COX-2), apoptotic markers (MMP, p53, Bax, Bcl-2, caspase-3 activity), cell cycle progression and cell survival status [total AKT (known as protein kinase B), phospho-AKT] in murine splenocytes. The size of the spleen has also been noted to evaluate splenomegaly.

\section{Materials and methods}

\section{Chemicals}

Paraquat dichloride, thiobarbituric acid (TBA), trichloroacetic acid (TCA), reduced glutathione, acrylamide-bis acrylamide, Tween 20, ethidium bromide (EtBr) and rhodamine 123 were purchased from Sigma-Aldrich (St. Louis, MO, USA), while fetal bovine serum
(FBS), antibiotics were obtained from HiMedia Laboratories (Mumbai, India). 2', $7^{\prime}$-Dichlorodihydrofluorescein diacetate $\left(\mathrm{H}_{2}\right.$ DCFDA), propidium iodide (PI) and hydrogen peroxide $\left(\mathrm{H}_{2} \mathrm{O}_{2}\right)$ were procured from Merck Chemicals (Germany). Antibodies were purchased from Cell Signalling Technology (Danvers, MA) and other chemicals used were of highest purity grade available.

\section{Animals}

Male Swiss albino mice, at 10-12 weeks old, weighing 24-30 were purchased from Chittaranjan National Cancer Institute (CNCI), Kolkata, India. Animals were maintained in the departmental animal facility under standard conditions $\left(24 \pm 2{ }^{\circ} \mathrm{C}, 50 \pm 5 \%\right.$ humidity) with $12 \mathrm{~h}$ light/dark cycle. Mice were given standard mice feed and water ad libitum. All mice were randomly assigned to experimental groups. All protocols for animal handling and research were duly approved by the 'Institutional Animal Ethics Committee' (IAEC-IV/proposal/SD-02/2012 dated 28.08.2014) under the guidelines of 'The Committee for the Purpose of Control and Supervision of Experiments on Animals (CPCSEA), Ministry of Environment, Forest and climate change, Government of India', at the Department of Physiology, University of Calcutta, India. Appropriate care was undertaken to minimize any accidental pain or injury to the animals.

\section{Treatment}

Mice received intra-peritoneal injections of PQ at a sub-lethal dose of $10 \mathrm{mg} \mathrm{kg}^{-1}$ body weight twice a week for 28 days (total of 8 doses) and the control group received the same volume of vehicle/ saline $(0.9 \% \mathrm{NaCl})$ intra-peritoneally. The dose of PQ was selected according to the dose-dependent effects of PQ on the survival of mice and the identification of a sub-lethal dose of PQ for the peripheral tissues of Swiss albino mice in the previous study. ${ }^{21}$

\section{Determination of spleen index}

After the sacrifice, the axial length of the spleen of both treated and control mice were measured by the standard scaling procedure. Body weight and spleen weight of both treated and control mice were also measured. The ratio of spleen weight/ body weight was represented as the spleen index in the Results section.

\section{Tissue lysate preparation}

After the completion of the final dose of PQ, the animals from both the treated and control groups were euthanized by cervical dislocation before the organs were dissected out. The spleen was homogenized using a tissue homogenizer (Sono Plus, Germany) in ice-cold $0.2 \mathrm{mM}$ phosphate buffer ( $\mathrm{pH} 7.4$ ) containing protease inhibitors (0.1 mM EDTA, 1.0 mM PMSF, $1 \mathrm{mM}$ DTT, $0.1 \mathrm{mM}$ EGTA, $0.3 \% \mathrm{NP}-40$ and $1 \mathrm{~g} \mathrm{~mL}^{-1}$ pepstatin A) to obtain a $10 \%(\mathrm{w} / \mathrm{v})$ tissue homogenate. The tissue homogenates were centrifuged at $12400 \mathrm{rpm}\left(30 \mathrm{~min}\right.$ at $4{ }^{\circ} \mathrm{C}$ ) in a cold centrifuge (Sorvall, USA). The supernatant was separated and recentrifuged at $13846 \mathrm{rpm}\left(30 \mathrm{~min}\right.$ at $\left.4{ }^{\circ} \mathrm{C}\right)$. The clear supernatant was taken for the analysis of post-mitochondrial fractions. The protein concentrations of samples were determined using 
the methods of Lowry et al. ${ }^{17}$ for further analysis of the biochemical and molecular parameters.

\section{Isolation of splenocytes}

Dissection of the mice followed the removal of the spleen and washing of the organs in $75 \%(\mathrm{v} / \mathrm{v})$ ethanol. Spleens were rewashed three times with phosphate buffer saline (PBS, pH 7.4). Using the plunger end of a syringe, spleens were dispersed in PBS and passed through a cell strainer $(40 \mathrm{~mm}$, SPL Life Sciences, Gyeonggi-do, South Korea) to obtain a homogeneous cell suspension following collection by centrifugation $\left(1000 \mathrm{rpm}, 10 \mathrm{~min}\right.$ at $4{ }^{\circ} \mathrm{C}$ ). The residual erythrocytes were lysed using RBC lysis buffer $\left(0.155 \mathrm{M} \mathrm{NH}_{4} \mathrm{Cl}, 0.1 \mathrm{mM}\right.$ EDTA, and $10 \mathrm{mM} \mathrm{KHCO}_{3}$ ) with minimal effect on splenocytes. The splenocytes were then washed twice in PBS and re suspended in RPMI-1640 containing $10 \%$ FBS and 100 units per mL of penicillin and streptomycin (HiMedia Laboratories, India). The cells were stimulated with concanavalin $\mathrm{A}\left(10 \mathrm{mg} \mathrm{mL}^{-1}\right)$ and incubated in $95 \%$ air and $5 \% \mathrm{CO}_{2}$, at $37{ }^{\circ} \mathrm{C} .{ }^{22}$

\section{Determination of iROS}

The iROS of splenocytes was determined by $\mathrm{H}_{2}$ DCFDA in flow cytometry. ${ }^{23} \mathrm{H}_{2}$ DCFDA is an ROS-sensitive compound that can easily diffuse into the cells and get hydrolyzed by an esterase to form DCHF within the cells, then is further oxidized by hydrogen peroxide or low-molecular-weight peroxides to produce the fluorescent compound $2^{\prime}, 7^{\prime}$-dichlorofluorescein. Splenocytes were suspended in PBS, with a saturating concentration of $\mathrm{H}_{2}$ DCFDA $(3 \mathrm{mM})$, in the dark for $30 \mathrm{~min}$ at room temperature. The DCFDA fluorescence signal was detected in flow cytometry using BD FACSCalibur (Becton Dickinson, Franklin Lakes, NJ) with $480 \mathrm{~nm}$ excitation and $530 \mathrm{~nm}$ emission light. For each sample, the auto fluorescence signal of unstained splenocytes was measured and used to adjust the fluorescence intensity of DCFDA stained splenocytes. Data were analyzed using standard FlowJo software (version 7.6.5). Analysis of the FL-1 fluorescence was performed with gating on the total unstained splenocytes population to identify the live splenocyte population. The same gate was used for all the samples to measure the FL-1 fluorescence intensity.

\section{Determination of LPO}

The formation of TBARS in the spleen cell lysate was calculated following standard protocol. ${ }^{24}$ In brief, the tissue homogenate was mixed with TCA (15\%), TBA $(0.35 \%)$ and $5(\mathrm{~N}) \mathrm{HCl}$ followed by incubation at $95{ }^{\circ} \mathrm{C}$ for $15 \mathrm{~min}$, following cooling and centrifugation. The absorbance of the supernatant was measured at $535 \mathrm{~nm}$ against an appropriate blank using a spectrophotometer (SmartSpec ${ }^{\mathrm{TM}}$ Spectrophotometer, BIO-RAD). The amount of lipid peroxidation in each sample was expressed in terms of TBARS produced in nanomoles per $\mathrm{mg}$ of protein.

\section{Determination of CAT activity}

CAT activity was measured using $\mathrm{H}_{2} \mathrm{O}_{2}$ with slight modification of the actual protocol. ${ }^{25}$ The cell lysate (containing $50 \mathrm{mg}$ of protein) was added to $50 \mathrm{mM}$ phosphate buffer ( $\mathrm{pH} 7$ ) containing $100 \mathrm{mM} \mathrm{H} \mathrm{H}_{2} \mathrm{O}_{2}$ and incubated for $2 \mathrm{~min}$ at $37^{\circ} \mathrm{C}$. The absorbance was monitored at $240 \mathrm{~nm}$ for 5 min using a spectrophotometer (SmartSpec $^{\text {TM }}$ Spectrophotometer, BIO-RAD). The change in absorbance with respect to time was proportional to the breakdown of $\mathrm{H}_{2} \mathrm{O}_{2}$. The CAT activity was expressed in units per $\mathrm{mg}$ protein, and one unit of enzyme activity was defined as the amount of enzyme required to break down $1 \mathrm{mM}$ of $\mathrm{H}_{2} \mathrm{O}_{2}$.

\section{Determination of SOD activity}

The activity of SOD was determined using the auto-oxidation of pyrogallol, ${ }^{26}$ which was adjusted during calculations. Briefly, $62.5 \mathrm{mM}$ tris-cacodylic acid buffer was added to the cell lysate, followed by the addition of $4 \mathrm{mM}$ pyrogallol. To monitor the auto-oxidation of pyrogallol, the absorbance was obtained at $420 \mathrm{~nm}$ in a spectrophotometer (SmartSpec ${ }^{\mathrm{TM}}$ Spectrophotometer, BIO-RAD) following the absorbance of the test samples, at specific time intervals.

\section{Determination of reduced GSH levels}

To determine GSH, the cell lysate was treated with $0.1 \mathrm{~mL}$ of $25 \%$ TCA and the resulting precipitate was pelleted by centrifugation at $7100 \mathrm{rpm}$ for $10 \mathrm{~min}$. The free endogenous sulfhydryl group was assayed in $3 \mathrm{~mL}$ of a mixture containing $2 \mathrm{~mL}$ of $0.5 \mathrm{mM}$ DTNB prepared in $0.2 \mathrm{M}$ phosphate buffer, with $1 \mathrm{~mL}$ of cell supernatant. The GSH reacted with DTNB and formed a yellow coloured complex, which was monitored at $412 \mathrm{~nm}$ in a spectrophotometer (SmartSpec ${ }^{\mathrm{TM}}$ Spectrophotometer, BIO$\mathrm{RAD}){ }^{27}$

\section{Determination of tissue nitrite formation}

Cellular nitrite formation was measured using the Griess reagent. ${ }^{28}$ Griess reagent $(990 \mu \mathrm{L})$ was mixed with $10 \mu \mathrm{L}$ of the cell lysate and incubated for $5 \mathrm{~min}$ at $37^{\circ} \mathrm{C}$ in the dark. The absorbance was read at $540 \mathrm{~nm}$ using a spectrophotometer (SmartSpec ${ }^{\mathrm{TM}}$ Spectrophotometer, BIO-RAD), and the value was calculated from the standard curve using $\mathrm{NaNO}_{2}$ solution (1 $\mathrm{mM})$.

\section{Determination of changes in MMP}

Both the control and treated splenocytes were seeded in 96-well plates at a density of $1 \times 10^{5}$ cells per $\mathrm{mL}$. Changes in MMP were monitored using the fluorescent dye rhodamine 123 . Depolarization of MMP in splenocytes results in the loss of rhodamine 123 from the mitochondria and a decrease in intracellular fluorescence was observed. Rhodamine 123 (final concentration of $10 \mu \mathrm{M}$ ) was added to the harvested cells and analyzed using a flow cytometer with the FlowJo software. ${ }^{29}$

\section{Analysis of cell cycle}

Cells from both groups were collected and washed twice with cold PBS. The cells were then fixed with $70 \%$ ethanol at $4{ }^{\circ} \mathrm{C}$, overnight. Cells were centrifuged for $5 \mathrm{~min}$ at $1000 \mathrm{rpm}$ at $4{ }^{\circ} \mathrm{C}$, after which the pellet was treated with $2 \mathrm{mg} \mathrm{mL}^{-1}$ RNase A at $37{ }^{\circ} \mathrm{C}$ for $20 \mathrm{~min}$ and stained with $50 \mathrm{mg} \mathrm{mL}{ }^{-1}$ propidium 
iodide (PI) containing $0.1 \%$ Triton $\mathrm{X}-100$ and EDTA $(0.02 \mathrm{mg}$ $\left.\mathrm{mL}^{-1}\right)$. Cells $\left(2 \times 10^{6}\right)$ were quantified to determine the distribution of different cell cycle phases using a BD FACSAria III flowcytometer (Becton Dickinson, Franklin Lakes, NJ, USA). The results were analyzed using the FlowJo software. ${ }^{30}$

\section{Analysis of CD4 and CD8 count}

The harvested splenocytes were washed twice using PBS and then incubated with anti-CD4-FITC and anti-CD8-PE conjugated antibodies for $2 \mathrm{~h}^{31}$ The stained splenocytes were subjected to flow cytometric evaluation using a BD FACSVerse flow cytometer.

\section{Immunofluorescence study}

This study was done to check the sub-cellular localization and expression level of Bax in splenocytes of the control and PQ treated group. Splenocytes were fixed with $4 \%$ paraformaldehyde following permeabilization using $0.2 \%$ Triton $\mathrm{X}$ 100. Then, a blocking solution ( $2 \%$ BSA and $0.1 \%$ Triton X-100 in PBS) was added for $1 \mathrm{~h}$ before the slides were incubated with primary antibody (at a ratio of $1: 250$ in the blocking solution). This step was followed by staining with FITC-labelled secondary antibodies for Bax (at a ratio of $1: 250$ each in the blocking solution, green fluorescence) and the nucleus of the cells were counterstained with $4^{\prime}$,6-diamidino-2-phenylindole (DAPI, Invitrogen, blue fluorescence). The slides were washed, followed by covering with mounting solution and visualized using the Olympus confocal microscope (Shinjuku, Tokyo, Japan). ${ }^{32}$ The relative fluorescence intensity of Bax was estimated from the intensity curve, and each immunofluorescence image was analyzed using ImageJ software.

\section{Immunoblot analysis}

Equal amounts of protein $(40 \mu \mathrm{g})$ were loaded in each lane on 12.5\% SDS-PAGE and transferred onto a PVDF membrane. After blocking with $5 \%$ bovine serum albumin (BSA) in TBST for $1 \mathrm{~h}$, the membranes were incubated with primary antibody overnight, followed by incubation with secondary antibody for $2 \mathrm{~h}$ at room temperature. Protein bands were visualized using NBTBCIP solution mixture. The relative protein levels were calculated by normalization to the amount of internal control protein. ${ }^{33}$ Monoclonal antibodies were used for phospho-AKT, total AKT, Bax, Bcl-2 (Cell Signalling Technology, Danvers, MA) and COX-2 (Santa cruz Biotechnology, Texas, USA). Polyclonal antibodies were used for p53 (Santa Cruz Biotechnology, Texas, USA), TNF- $\alpha$ and IL-6 (Imegenex, San Diego, CA, USA). $\beta$ Actin and GAPDH (Cell Signalling Technology, Danvers, MA) were used as loading controls.

\section{Determination of protein expression using flow cytometry}

Splenocytes were fixed with $4 \%$ paraformaldehyde in PBS $(\mathrm{pH}$ 7.4) for $20 \mathrm{~min}$ at room temperature and permeabilized using $0.1 \%$ Triton $\mathrm{X}-100$ in PBS with $0.1 \%$ FBS for 5 min. After washing twice in PBS with $3 \%$ FBS, the permeabilized splenocytes were incubated with primary antibody on ice for $2 \mathrm{~h}$ and washed twice with PBS. The cells were then incubated with
FITC-conjugated goat anti-rabbit IgG as a secondary antibody for $30 \mathrm{~min}$ on ice and washed twice in PBS. The stained cells were acquired and then analyzed using a BD FACSCalibur flow cytometer (Becton Dickinson, Franklin Lakes, NJ, USA) equipped with FlowJo software. ${ }^{34}$

\section{Determination of caspase-3 activity}

The enzymatic activity of caspase-3 was measured according to the manufacturer's instructions (BioVision, Inc., Mountain View, CA, USA) using a caspase-3/CPP32 fluorometric assay kit. For the caspase-3 assay, equal amounts of lysates were incubated with $50 \mu \mathrm{L}$ of reaction buffer containing $10 \mathrm{mM}$ dithiothreitol and $50 \mu \mathrm{M}$ caspase fluorometric substrates (DEVD-AFC) at $37{ }^{\circ} \mathrm{C}$ for $1 \mathrm{~h}$. The fluorescence of the released AFC was measured with a fluorimeter (JASCO, India) using excitation and emission wavelengths of 400 and $505 \mathrm{~nm}$, respectively. ${ }^{21}$

\section{Statistical analysis}

All data were presented as mean \pm standard error of the mean (SEM). The significant differences between the PQ treated and the control groups were determined by the one-tailed Student's $t$-test using the software OriginLab 8.0. In all cases, a value of $p<$ 0.05 was considered as significant.

\section{Results}

\section{PQ induced splenomegaly in mice}

The mice of the PQ-treated group developed splenomegaly (Fig. 1A). The axial length of the spleen was increased significantly $(p<0.05)$ in the PQ-treated group, compared to the

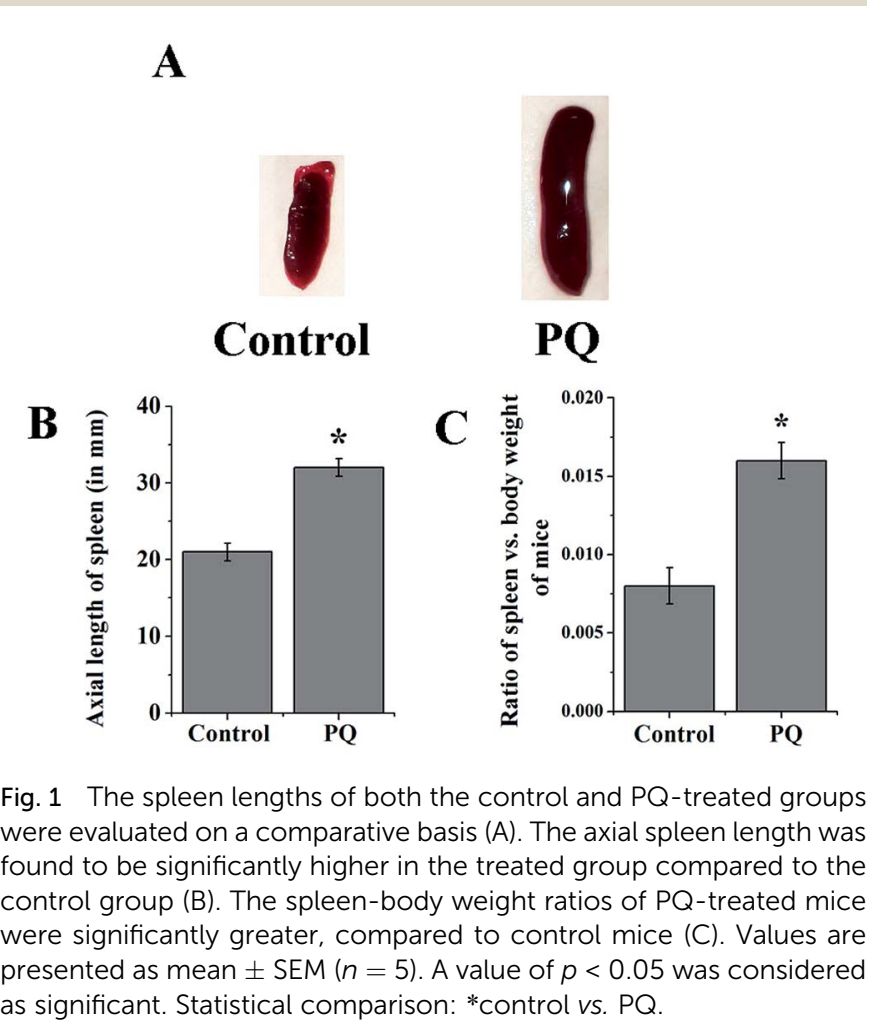




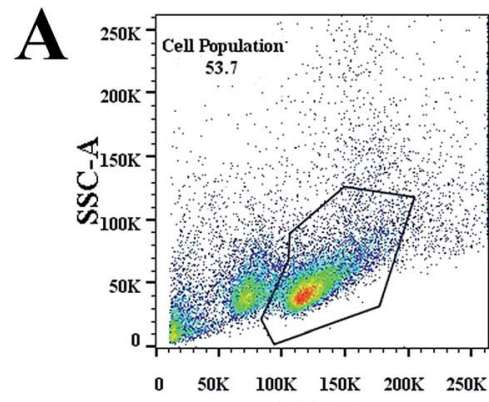

FSC-A

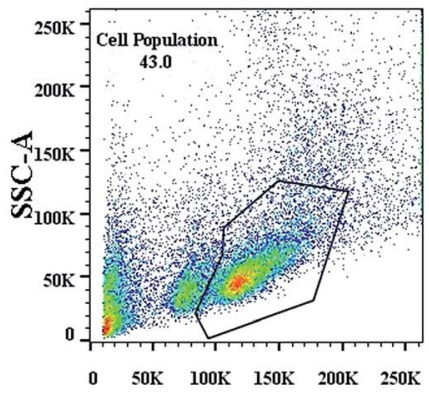

FSC-A

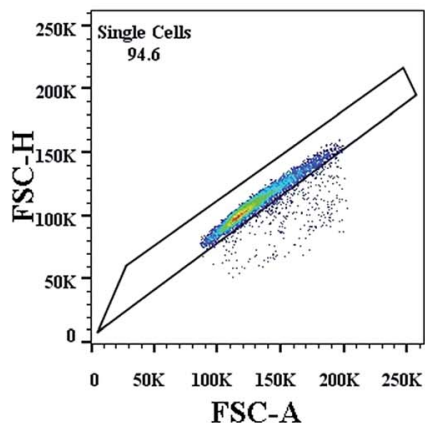

FSC-A

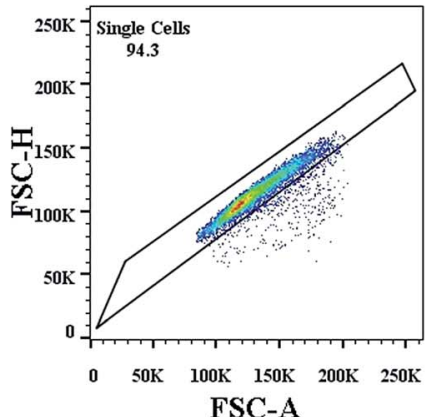

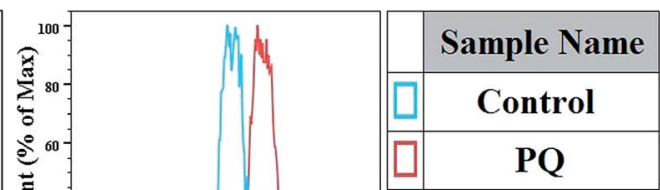
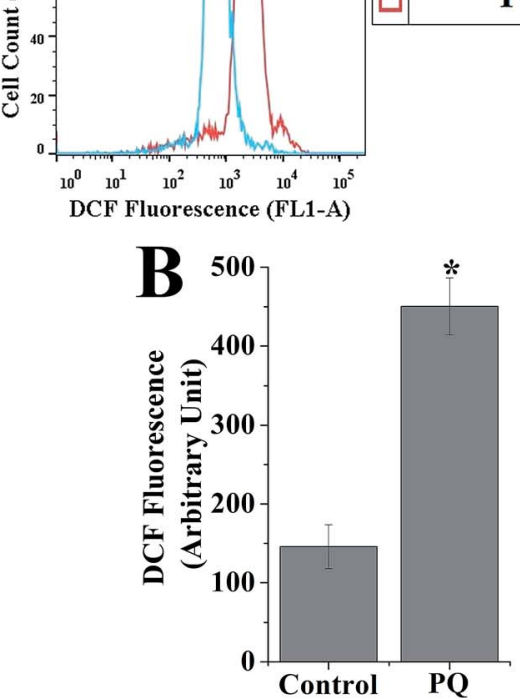

Fig. $2 \mathrm{PQ}$-Induced intracellular ROS generation in splenocytes was determined using flow cytometry. (A) Representative histograms showing DCF fluorescence in the control and PQ treated cells. (B) Quantitative analysis of the relative fluorescence intensity of DCF in the control and PQ treated cells. Values are presented as mean $\pm \operatorname{SEM}(n=5)$. A value of $p<0.05$ was considered as significant. Statistical comparison: *control vs. PQ.
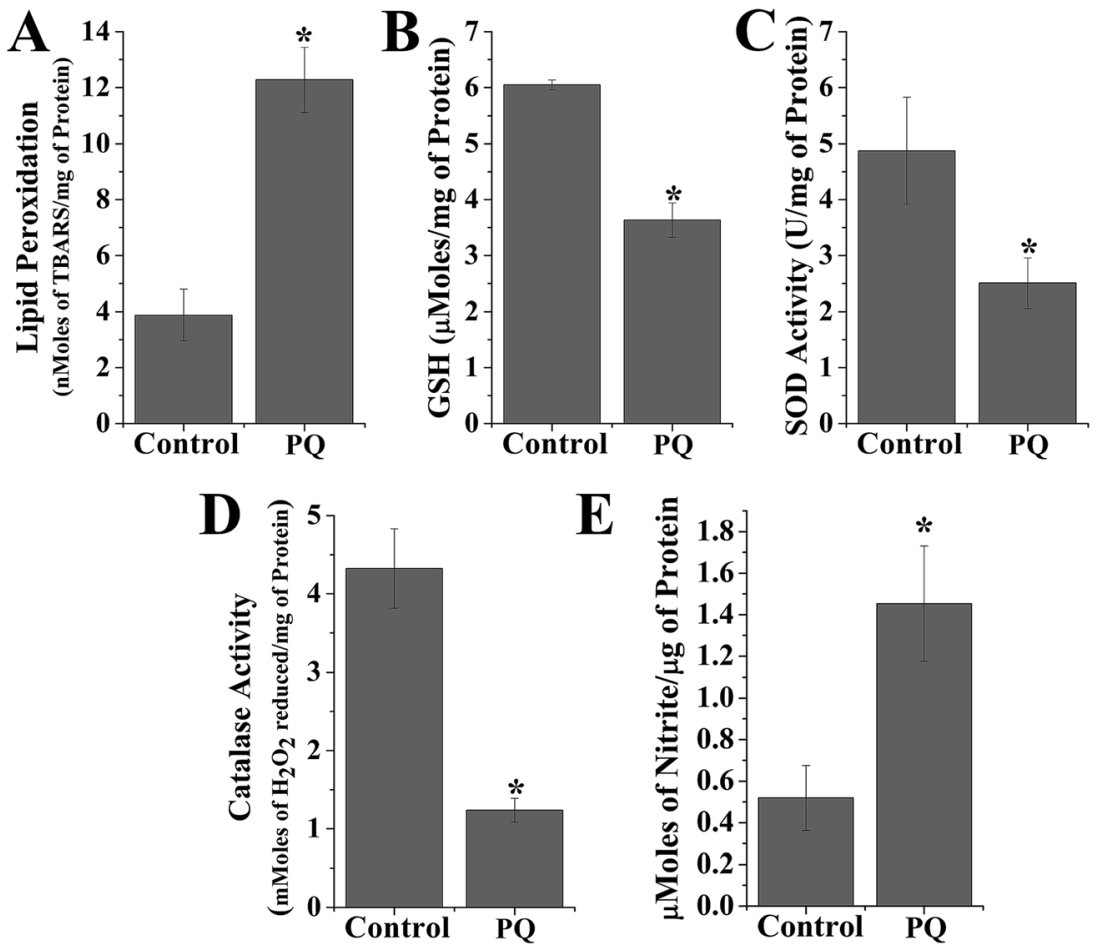

Fig. 3 Representative bar graphs showing lipid peroxidation, antioxidant parameters and tissue nitrite formation. In all these cases, values are presented as mean \pm SEM $(n=5)$. A value of $p<0.05$ was considered as significant. Statistical comparison: *control vs. PQ. (A) LPO of spleen tissue homogenate in terms of TBARS (nmoles of TBARS per mg of protein), (B) PQ-induced alteration of reduced glutathione ( $\mu$ moles per mg protein) in mice spleen homogenates, (C) $P Q$-induced alteration of superoxide dismutase activity (unit activity per mg protein) in murine spleen homogenates. (D) PQ-Induced alteration of catalase activity (mmoles $\mathrm{H}_{2} \mathrm{O}_{2}$ reduced per $\mathrm{mg}$ of protein) in murine liver homogenates. (E) PQInduced alteration of tissue nitrite formation ( $\mu$ moles of nitrite per $\mu \mathrm{g}$ of protein) in murine spleen homogenates. 
control (Fig. 1B). In addition, the spleen-body weight ratio was also measured in the control and PQ-treated mice group. The ratio of spleen weight and body weight was significantly $(p<0.05)$ greater in the PQ-treated group compared to the control (Fig. 1C).

\section{PQ mediated ROS generation}

Fig. 2B shows that the relative DCF fluorescence intensity was significantly $(p<0.05)$ higher $(3.09$-fold) in the PQ-treated group compared to that of the control group.

\section{PQ increased TBARS and tissue nitrite formation}

PQ treatment increased TBARS formation in splenic cells. In the present study, cellular TBARS formation was significantly $(p<0.05)$ higher $(3.17$-fold) in the PQ-treated group compared to that of the control group, indicating the oxidative degradation of cellular membrane lipids (Fig. 3A). PQ also significantly $(p<0.05)$ increased the cellular nitrite level (2.8-fold), compared to the levels in the control cells (Fig. 3E) of mice spleen.
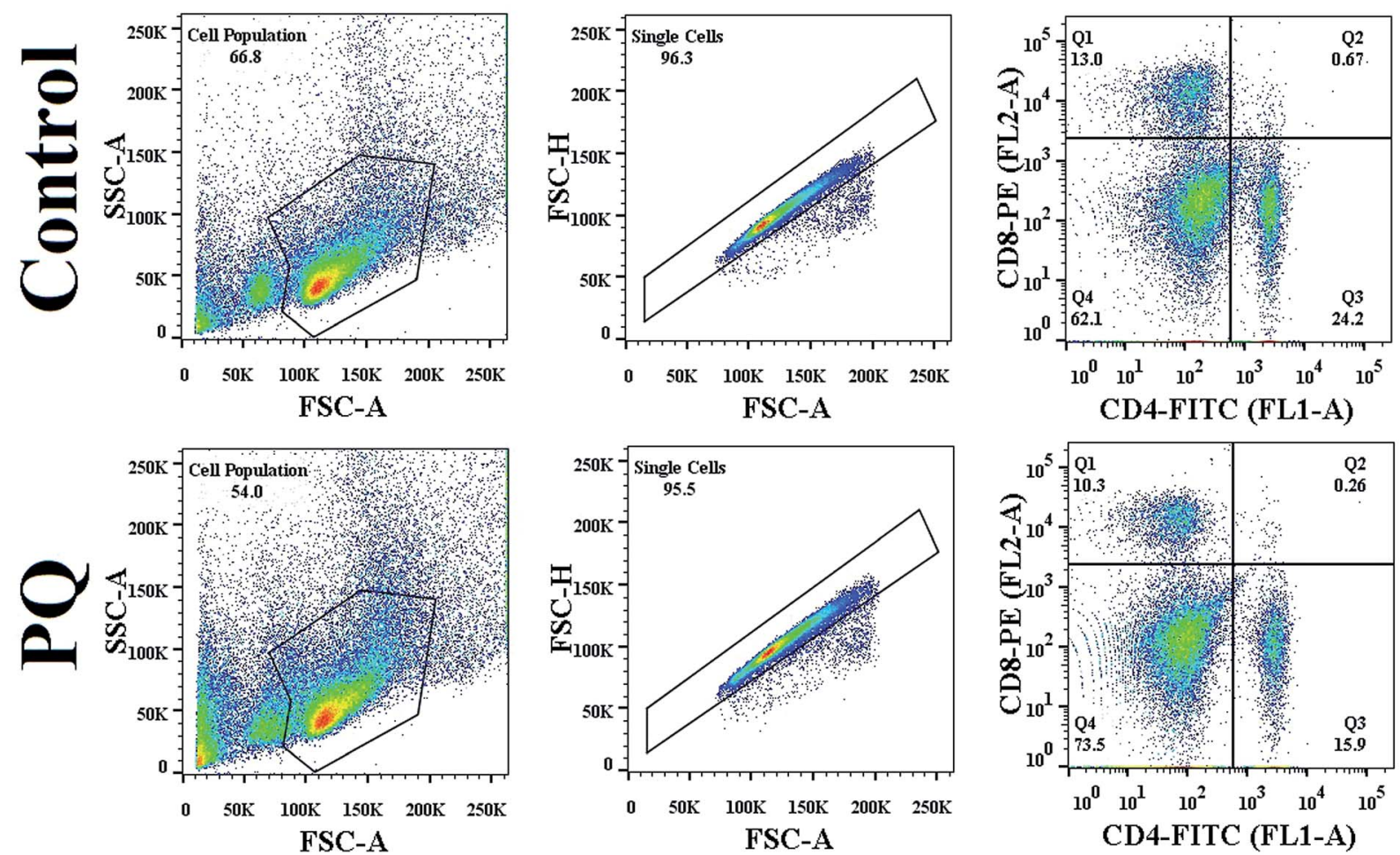

Fig. 4 PQ-Induced change in CD4/CD8 count in murine splenocytes. Splenocytes were chosen on the basis of the SSC vs. FSC plot, and doublet population of total splenocytes were gated out on the basis of the FSC-H vs. FSC-A plot. Quantitative analysis of CD4/CD8 count was done using FlowJo software.
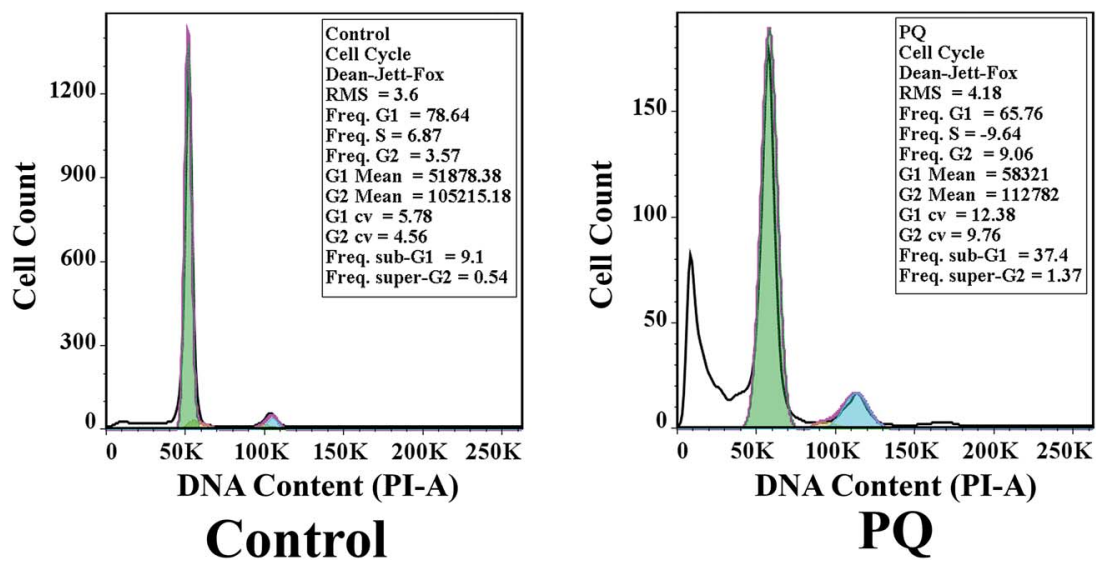

Fig. 5 Histograms showing DNA content of cell cycle progression in splenocytes of control and PQ-treated groups. The percentage of cell populations in various phases (G1, S, G2/M and sub G1 phase) of the cell cycle was analyzed using a BD FACSAria III flow cytometer, and the results were analyzed using FlowJo software. 
PQ-Induced depletion of non-enzymatic and enzymatic antioxidants

The GSH level decreased (0.6-fold) and activity of other antioxidant enzymes (SOD and CAT) were significantly reduced (0.51fold for SOD and 2.9-fold for CAT) in the PQ-treated group compared to the control group (Fig. 3B-D).

\section{T cell phenotypic changes mediated by $P Q$}

To evaluate the altered differentiation in the PQ-treated splenocyte population, the cell surface marker for each subpopulation was evaluated using flow cytometry. PQ altered each subpopulation, $\mathrm{CD}^{+}$cells decreased from $24.2 \%$ to $15.9 \%$ and $\mathrm{CD}^{+}$cells also decreased from $13.0 \%$ to $10.3 \%$, as clearly shown in Fig. 4. The reduction in both $\mathrm{CD}^{+}$and $\mathrm{CD} 8^{+}$cells indicated the PQ-induced onset of immunocompromised situations in mice.

PQ increased the sub G0/G1 population and arrested the cell cycle at G1/S in murine splenocytes

To confirm whether PQ induced apoptosis in murine splenocytes, flow cytometry was employed. The cell cycle phase distribution of DNA content was determined, and treatment with PQ significantly increased the percentage of DNA content in the sub G0/G1 population from $9.1 \%$ to $37.4 \%$, indicating cell cycle arrest at the sub G0/G1 stage (Fig. 5). On the other hand, the percentage of splenocytes in the $S$ phase was decreased in the PQ-treated mice group, compared to the control mice group.

\section{PQ-Induced changes in the MMP of murine splenocytes}

To evaluate the role of $\mathrm{PQ}$ in the reduction of the MMP of splenocytes in mice, a flow cytometry assay was done using the mitochondrial specific fluorescent probe rhodamine 123 . Fig. $6 \mathrm{~B}$ reveals that $\mathrm{PQ}$ treatment significantly decreased the relative rhodamine 123 fluorescence intensity over the control group in the splenocytes of mice.

\section{PQ-Induced activation of p53 and apoptosis in splenocytes through the mitochondria dependent pathway}

To determine the PQ activated mitochondria dependent apoptosis pathway in murine splenocytes, we examined the protein expression pattern of p53, Bax and Bcl-2 in splenocytes. Levels of p53 were drastically elevated in the PQ-treated group (2.36 fold) with respect to the control group. Immunoblot analysis also revealed that $\mathrm{PQ}$ caused significant up regulation in Bax (2.05 fold), as well as a down regulation in Bcl-2 (0.52 fold) expressions as compared to the control group (Fig. 7A and B). These results were further clarified by flow cytometry analysis. Results showed that PQ markedly increased the p53 expression in the splenocytes, compared to the control cells (Fig. 8A and B). Moreover, Bax expression also increased (Fig. 8C and D) significantly ( $p<0.05)$, and the expression level of Bcl-2 decreased (Fig. 8E and F) in the PQ group compared to the control group, as observed from the FITC relative fluorescence intensity. The Bax expression level was further assessed by immunofluorescence study. Results showed that Bax expression

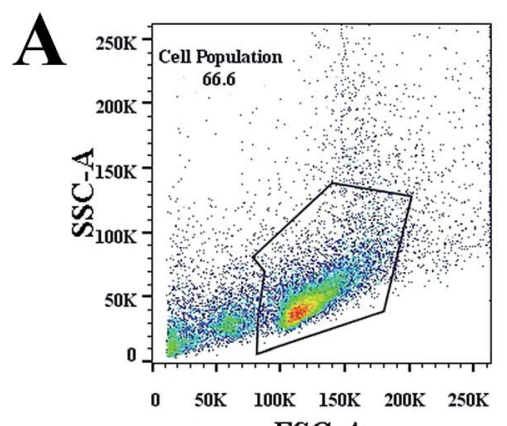

FSC-A

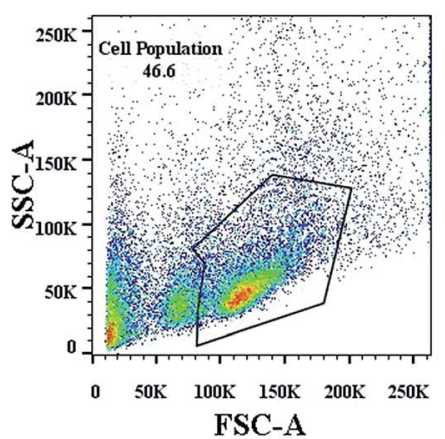

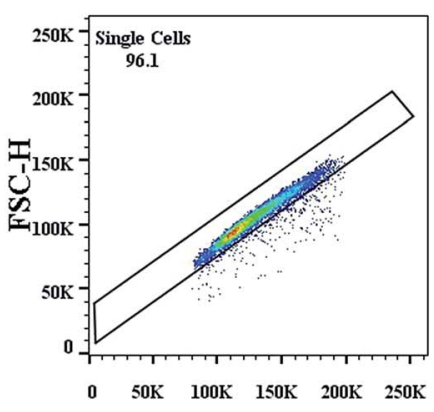

FSC-A

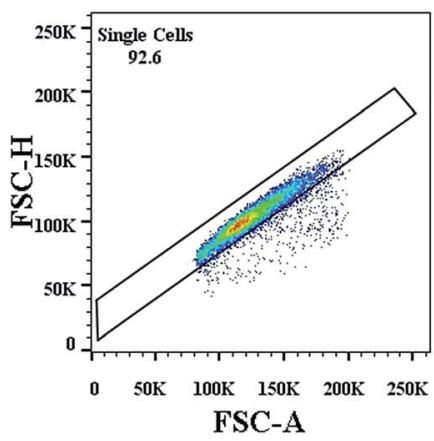

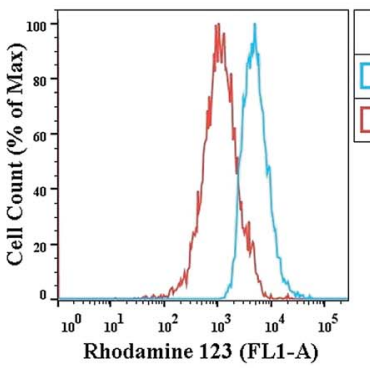

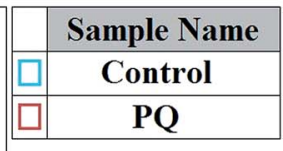

B

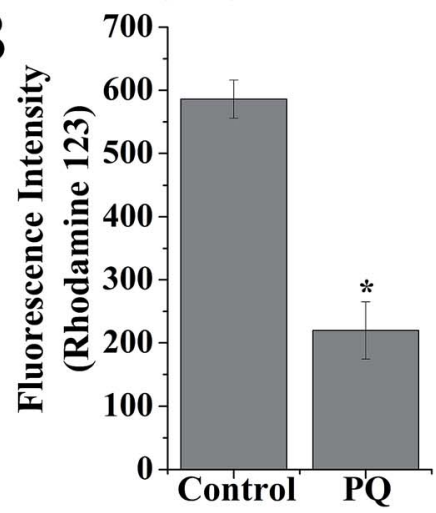

Fig. 6 PQ-Induced changes in mitochondrial membrane potential in murine splenocytes. (A) Splenocytes were chosen on the basis of the SSC vs. FSC plot, and the doublet population of total splenocytes were gated out on the basis of the FSC-H vs. FSC-A plot. Respective histograms of relative fluorescence intensity of rhodamine 123 were analyzed using FlowJo software. (B) Graph showing quantitative analysis of relative fluorescence intensity of rhodamine 123. $p<0.05$ was considered as significant $(n=5)$. Statistical comparison: *control vs. PQ. 

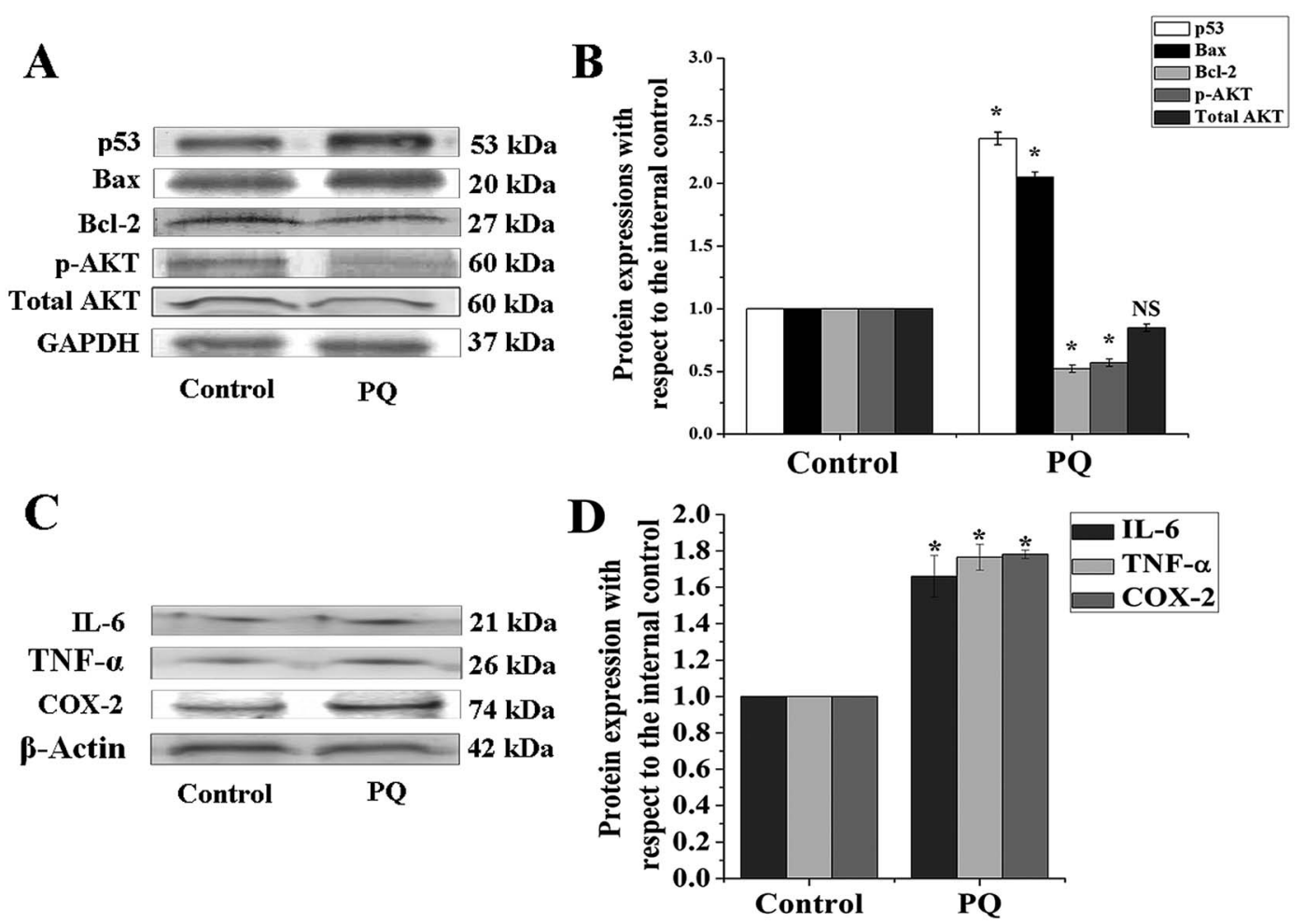

Fig. 7 PQ-Induced expression of apoptosis, cell survival and pro-inflammatory proteins. (A) Immunoblot analysis was performed using specific antibodies for p53, Bax, Bcl-2, pAKT and total AKT, and GAPDH was used as the loading control. (B) Relative intensities were obtained from densitometric analysis of the respective immunoblots. (C) Immunoblot analysis was performed using specific antibodies for TNF- $\alpha$, IL- 6 and COX-2, and $\beta$-actin was used as a loading control. (D) Relative intensities were obtained from densitometric analysis of the respective immunoblots. Values are presented as mean $\pm \operatorname{SEM}(n=5)$. A value of $p<0.05$ was considered as significant. Statistical comparison: *control vs. PQ (10 $\mathrm{mg} \mathrm{kg}^{-1}$ of body weight).

apparently increased with PQ treatment in mice splenocytes (Fig. 9).

\section{PQ-Induced changes in caspase-3 activity}

Caspase-3 activity was significantly higher (2.27 fold) in the splenocytes of the PQ-treated group compared to that of the control mice groups $(p<0.05)$ (Fig. 10).

\section{PQ treatment down regulated the expression of the cell survival marker}

AKT serves as a key protein involved in cellular survival and growth in response to extracellular signals. In the present study, results demonstrated that AKT was hypophosphorylated (0.57 fold) in the PQ treated group, compared to the control group (Fig. 7A and B). Interestingly, the change in total AKT expression remained non-significant between the control and treated group, suggesting that PQ treatment markedly reduced AKT phosphorylation, followed by the suppression of cellular survival in murine spleen.

The status of pro-inflammatory indices in murine splenocytes after PQ treatment

Cytokines such as TNF- $\alpha$ and IL-6 are involved in the early proinflammatory phase of PQ poisoning. In this study, we assessed
TNF- $\alpha$ and IL-6 expression levels in murine splenocytes after PQ treatment. The results show that PQ strongly promoted TNF$\alpha$ (1.76 fold) and IL-6 (1.66 fold) expressions in splenocytes with respect to the control group in mice. On the other hand, COX-2, another pro-inflammatory biomarker was significantly $(p<0.05)$ increased (1.78 fold) in the PQ treated group, compared to the control mice group (Fig. 7C and D).

\section{Discussion}

To the best of our knowledge, the downbeat effects of exposure to environmentally relevant toxicants on murine splenocytes have not been previously reported. This study reports for the first time that the intracellular events associated with PQinduced splenomegaly, oxidative stress and compromised antioxidant pool lead to the activation of the downstream pathways of inflammation, immunomodulation and apoptosis in murine splenocytes.

A recent study indicated that PQ damages the splenocytes and their cellular morphology in Swiss albino mice. ${ }^{35}$ In our study, splenomegaly was a major observation after PQ treatment. The gain in spleen weight might be associated with the expansion of red pulp (damaged RBCs) area and is also consistent with stress erythropoietic response. The splenomegaly interferes with the filtration process in animals. The 
A

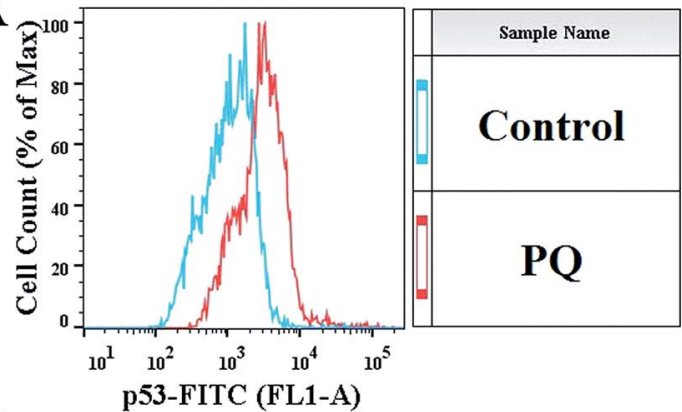

$\mathcal{C}$

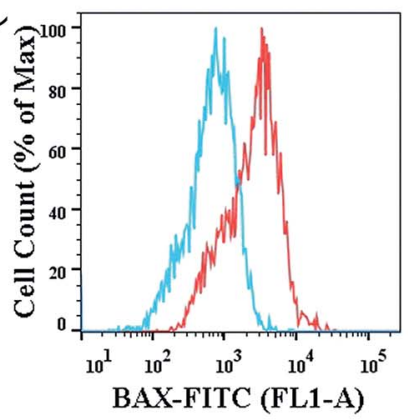

E

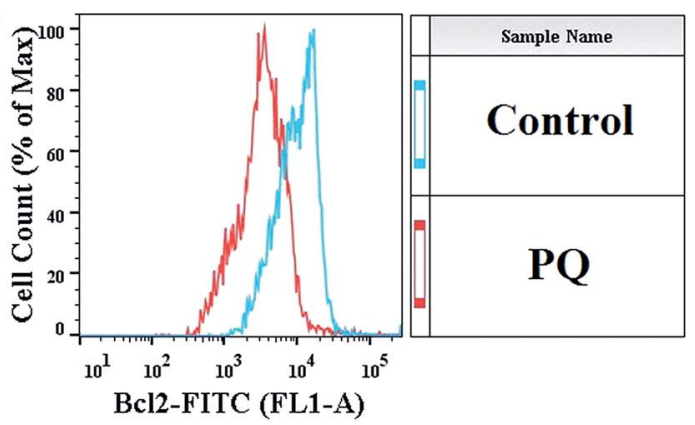

B

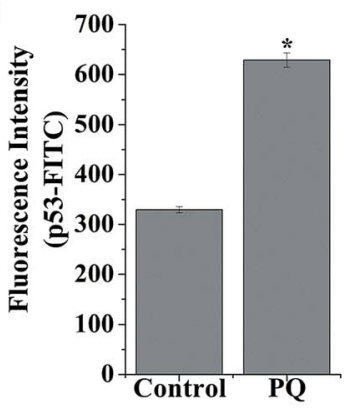

D

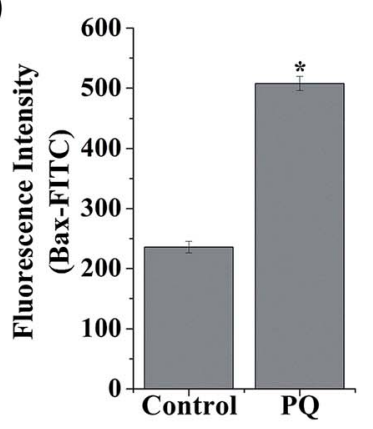

F

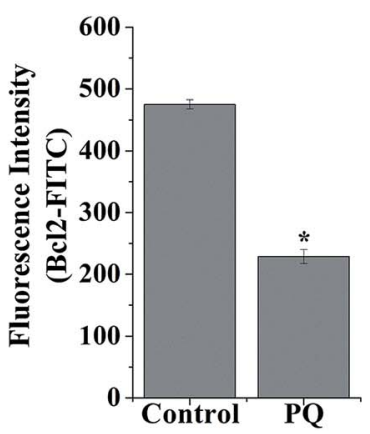

Fig. 8 (A, C and E) Relative FITC fluorescence intensities of p53, Bax, Bcl-2 expression were obtained from flow cytometric analysis. (B, D and F) Histograms represent flow cytometric analysis of $\mathrm{p53}$, Bax, and Bcl-2 expression. Values are presented as mean $\pm \mathrm{SEM}(n=5)$. A value of $p<0.05$ was considered as significant. Statistical comparison: *control vs. PQ $\left(10 \mathrm{mg} \mathrm{kg}^{-1}\right)$ of body weight.

spleen weights exceeding the normal reference ranges were considered important indicators of potential immunotoxicity. ${ }^{35}$ The most plausible explanations for this are the inhibition of lymphocyte proliferation and the induction of lymphocyte apoptosis in spleen.

High dose of PQ-mediated ROS generation is correlated with devastating organ failure beyond the major target organs (the heart, lungs, liver, and kidneys), which involve mitochondrial, microsomal and cytosolic enzymes in both animals and humans, to combat the challenge of toxic insults. ${ }^{36-39}$ Redox cycling is believed to play an important role in the injury of cells by PQ. ${ }^{40}$ ROS generation plays dual or bi-phasic roles, and has essential protective as well as destructive roles in the immune system. ${ }^{\mathbf{4 1 , 4 2}}$ From our results, it appeared that PQ generates oxidative stress in the spleen, as was indicated by increased cellular ROS levels and compromised antioxidant profiles in treated mice (Fig. 2). There was a decrease in GSH levels (Fig. 3B), reduction in SOD and CAT activities (Fig. 3C and D), including enhanced lipid peroxidation (Fig. 3A) in the PQ treated group, compared to the control. Thus, the toxic insults have promulgated broad spectrum molecular events. In addition, reactive nitrogen species (RNS) were also increased, as was indicated by increased tissue nitrite formation in PQ treated mice (Fig. 3A and E). Nitrites constitute a biochemical reservoir for nitric oxide (NO) in mammals. The reduction of nitrite to NO is catalyzed by many metal-containing enzymes that increase under hypoxic or ischemic conditions. ${ }^{\mathbf{4 3}}$ Administration of exogenous nitrites in humans and rodents is clearly associated with NO-like bioactivity, as demonstrated by the increase in cGMP formation, vasodilatation, reduction in blood pressure, inhibition of platelet function, and protection against ischemiareperfusion injury. Nitrates, nitrites, NO, and their reaction products have significant roles in glucose-insulin homeostasis, including the regulation of microvascular blood flow, mitochondrial function, insulin secretion, gluconeogenesis, and glucose uptake, as well as modulating the inflammatory reaction and oxidative stress in different pathways. ${ }^{44}$ The nascent NO diffuses out from the cells and binds to the heme group of 


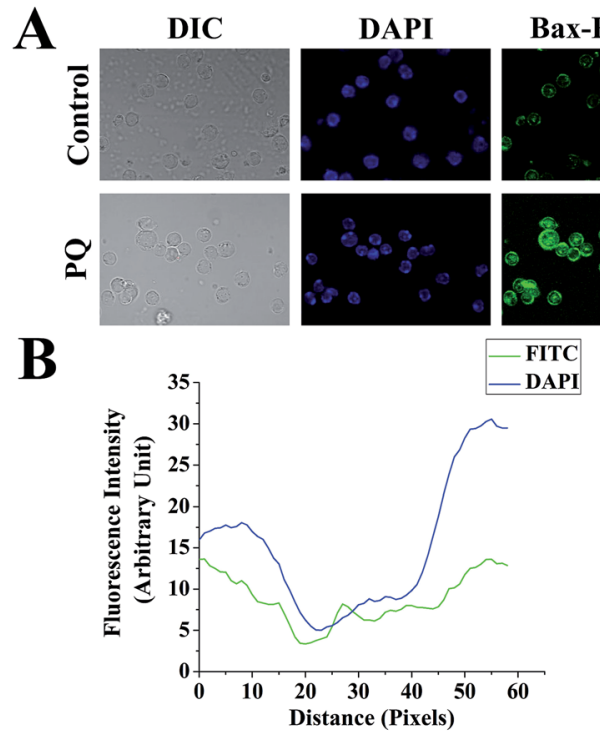

Control

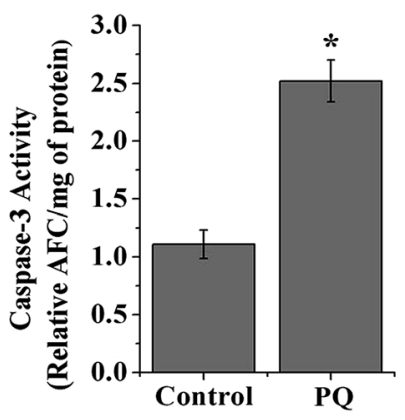

Fig. 10 The graph represents caspase-3 activity in splenocytes of the control and $P Q$-treated mice groups. Values are presented as mean \pm $\operatorname{SEM}(n=5)$. A value of $p<0.05$ was considered as significant. Statistical comparison: *control vs. $\mathrm{PQ}$.

cytosolic guanylate cyclase to activate the enzymes in nearby target cells. This interaction represents a novel and widespread signal transduction mechanism that links extracellular stimuli to the biosynthesis of cGMP in nearby target cells. ${ }^{45} \mathrm{~A}$ recent study has shown that NO plays the role of mediator in the pathogenesis of PQ-induced lung injury. ${ }^{\mathbf{4 6}}$ Therefore, our above results indicate that ROS and RNS wreaked havoc after PQ treatment in mice splenocytes, which remain as responsible agents leading to cellular DNA damage, apoptosis and loss of MMP.

All these events may also be responsible for the onset of immunosuppression and/or immunomodulation. Previous reports indicate that ROS interfere with the T-cell receptor signaling pathways. In different disease conditions, the redox status of T-cell subtypes varies and these variations can modulate the immune response in humans. ${ }^{47}$ Even though this study did not assess functional immunity, it undertook a very brief phenotypic analysis of immune cells following herbicide exposure.

We investigated the spleen $\mathrm{T}$ lymphocyte subsets after PQ exposure with flow cytometry. The $\mathrm{CD} 4^{+}$and $\mathrm{CD} 8^{+}$subsets of $\mathrm{T}$ lymphocytes are primarily involved with the immune responses to specific antigenic challenges and in immune regulation. However, we found that PQ had an impact on both $\mathrm{CD} 4^{+}$and $\mathrm{CD}^{+} \mathrm{T}$ cells (Fig. 4), resulting in a change in the ratio of $\mathrm{CD} 4^{+}$/ $\mathrm{CD}^{+}$cells in the spleen. Thus, PQ toxicity to immune cells is reflected in diminished $T_{H}$ and enhanced $T_{c}$ cell count in the spleen, supporting splenocyte apoptosis. Other studies have reported that a number of chemically-induced immunotoxic effects are characterized as immunosuppressive effects, which manifest as marked decreases in immune function, as well as splenomegaly, inhibition of immune cell function or even apoptosis of lymphocytes. ${ }^{48}$

Another major change found was that PQ treatment enhanced the sub G0/G1 population of the cell cycle; therefore, PQ triggered apoptosis might be induced in some fractions of the cells existing in the sub G0/G1 phase, which are committed to G0/G1 arrest. Moreover, it arrested the cells at the G1/S checkpoint. The rate of cell division is crucial for normal growth, development and maintenance; p53 plays a role in regulating checkpoints during the G1 and G2 phases of the cell cycle, as p53 mediates cell cycle arrest or apoptosis after DNA damage. ${ }^{49}$

In this study, we observed that the administration of PQ upregulated p53, Bax protein expressions and down-regulated Bcl2 protein expression (Fig. 7A and B). Different in vitro studies 
supported the fact that PQ also induces the mitochondria mediated cellular apoptosis through changes in Bax and Bcl-2 expression levels. ${ }^{50,51}$ Furthermore, we found that the activity of caspase-3, an effector molecule of apoptosis that plays a key role in linking the commitment and degradation phases, significantly increased in the splenocytes in PQ treated mice compared to control mice (Fig. 10). Both in vivo and in vitro reports with PQ induced caspase-3 activation in brain cells are consistent with our findings. ${ }^{\mathbf{5 1}}$ Moreover, the AKT/PI3K pathway plays a central role in integrating various cellular stimuli with a broad range of cellular functions. AKT further regulates an array of downstream targets involving cell survival, cell growth and cell proliferation, including members of the Bcl-2 family. ${ }^{52}$ Activation of AKT (on phosphorylation) is linked to p53 inhibition and cell survival. ${ }^{53}$ The mutual antagonism between p53 and AKT mediated an essential role as they have opposite effects on apoptosis. These considerations helped us to hypothesize that the p53-AKT network is an important module that controls pathways to cell survival or death. We found that the total-AKT expression level was unaltered in PQ treated mice splenocytes. However, the phosphorylated-AKT level decreased after PQ treatment in the spleen of male Swiss albino mice (Fig. 7A and B). These results emphasized the involvement of p53-AKT axis involvement in pushing the splenocytes towards death.

In addition, the herbicide PQ led to inflammatory development. The pro-inflammatory molecules, such as IL-6, TNF- $\alpha$ and COX-2 expressions were enhanced in murine splenocytes (Fig. 7C and D). PQ-Induced ROS accumulation promulgated the production of TNF- $\alpha$ and IL-6, resulting in tissue injury; on the other hand, increased TNF- $\alpha$ and IL- 6 concentrations promoted ROS generation. This vicious cycle may have subsequently initiated an inflammatory cascade that aggravated tissue damage. Literature indicates that the PQ-induced accumulation of ROS can also activate intracellular transcription factors such as p38-MAPK and NF- $\mathrm{B}$, which coordinate the expression of many genes for pro-inflammatory and innate immune

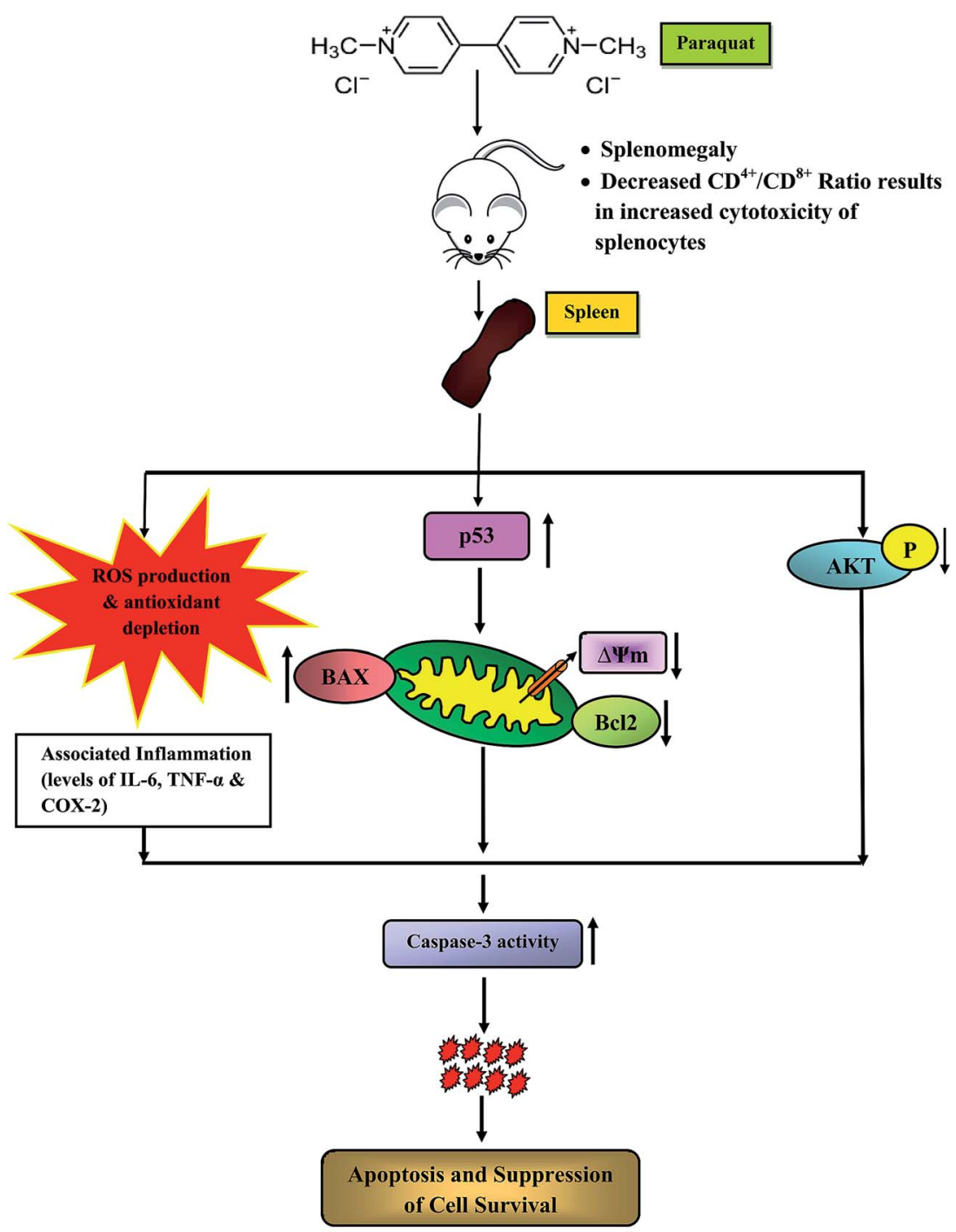

Paraquat-induced Imbalance of Splenic Redox Homeostasis

Fig. 11 Schematic representation of the proposed mechanism for the toxic effects of paraquat and related molecular events on murine spleen. 
responses, as well as genes encoding pro-inflammatory chemokines and cytokines. ${ }^{54}$ The pathogenesis of $\mathrm{PQ}$ induced lung injury specify that these pro-inflammatory cytokines promote fibrogenesis, either alone or associated with other cytokines. ${ }^{55,56}$ These results validated the present results, showing that PQ evoked inflammation in murine spleen. This low grade inflammation might be the reason for the increased size of the spleen in PQ treated mice, compared to the control (Fig. 1).

\section{Conclusion}

The current study provides a new insight into the molecular mechanisms of PQ-induced stress response and toxicity in splenocytes (Fig. 11), and is the first to convey information on the cellular events related to $P Q$ induced oxidative damage manifesting phenotypic changes in the spleen, which activate the molecular events of apoptosis and inflammation. We support our claim with the evidence of increased sub G0/G1 cell population, depletion of MMP, increase in the expression of pro-inflammatory molecules (TNF- $\alpha$, IL-6, COX-2) and proapoptotic factors (p53, Bax), decrease in the expression of anti-apoptotic factors (Bcl-2), increase in caspase-3 activity and subsequent DNA damage. Furthermore, we have identified that this exotoxic agent made the organism less immune tolerant by diminishing $\mathrm{T}_{\mathrm{H}}$ and enhancing $\mathrm{T}_{\mathrm{c}}$ cell count in the spleen. The present study has established factual evidence in terms of critical biomarkers associated with herbicide induced toxicity in mammalian systems, and has the potential for providing clinical benefits.

\section{Abbreviations}

$\begin{array}{ll}\text { PQ } & \text { Paraquat } \\ \text { LPO } & \text { Lipid peroxidation } \\ \text { TBARS } & \text { Thiobarbituric acid reactive substance } \\ \text { CAT } & \text { Catalase } \\ \text { GPx } & \text { Glutathione peroxidase } \\ \text { iROS } & \text { Intracellular reactive oxygen species } \\ \text { MMP } & \text { Mitochondrial membrane potential } \\ \text { RBC } & \text { Red blood cell }\end{array}$

\section{Acknowledgements}

The authors have declared no conflict of interest. The authors gratefully acknowledge CRNN and DBT-IPLS, University of Calcutta, for providing research facilities. We are specifically thankful to University Grant Commission (UGC, Govt. of India) under the Centre with Potential for Excellence in Particular Area (CPEPA) scheme [F. No. 8-2/2008 (NS/PE), dated 14/12/2011], granted to the University of Calcutta for major funding support. The authors also acknowledge the Council of Scientific and Industrial Research (CSIR) and Life Science Research Board (LSRB) for their funding support. Appreciation is extended to UGC, Govt. of India again for providing research fellowship to Aaveri Sengupta.

\section{References}

1 M. F. Cesta, Normal Structure, Function, and Histology of the Spleen, Toxicol. Pathol., 2006, 34, 455-465.

2 B. Riahi, H. Rafatpanah, M. Mahmoudi, B. Memar, A. Brook, N. Tabasi and G. Karimi, Immunotoxicity of paraquat after subacute exposure to mice, Food Chem. Toxicol., 2010, 48, 1627-1631.

3 K. C. Fussell, R. G. Udasin, J. P. Gray, V. Mishin, P. J. Smith, D. E. Heck and J. D. Laskin, Redox cycling and increased oxygen utilization contribute to diquat-induced oxidative stress and cytotoxicity in Chinese hamster ovary cells overexpressing NADPH-cytochrome $\mathrm{P} 450$ reductase, Free Radical Biol. Med., 2011, 50, 874-882.

4 M. Jimenez-Del-Rio, G. Suarez-Cedeno and C. Velez-Pardo, Using paraquat to generate anion free radicals and hydrogen peroxide in vitro: Antioxidant effect of vitamin E, Biochem. Mol. Biol. Educ., 2010, 38, 104-109.

5 T. Fukushima, K. Tanaka, H. Lim and M. Moriyama, Mechanism of cytotoxicity of paraquat, Environ. Health Prev. Med., 2002, 7, 89-94.

$6 \mathrm{X}$. Li and A. Y. Sun, Paraquat induced activation of transcription factor AP-1 and apoptosis in PC12 cells, $J$. Neural Transm., 1999, 106, 1-21.

7 R. A. Gonzalez-Polo, A. Rodriguez-Martin, J. M. Moran, M. Niso, G. Soler and J. M. Fuentes, Paraquat-induced apoptotic cell death in cerebellar granule cells, Brain Res., 2004, 1011, 170-176.

8 J. Choi, J. Ritchey, J. L. Prior, M. Holt, W. D. Shannon, E. Deych, D. R. Piwnica-Worms and J. F. DiPersio, In vivo administration of hypomethylating agents mitigate graft versus-host disease (GvHD) without sacrificing graft-versus leukemia (GvL), Blood, 2010, 12, 257253.

9 M. Thiruchelvam, E. K. Richfield, R. B. Baggs, A. W. Tank and D. A. Cory-Slechta, The nigrostriatal dopaminergic system as a preferential target of repeated exposures to combined paraquat and maneb: Implications for Parkinson's Disease, J. Neurosci., 2000, 20, 9207-9214.

10 M. Niso-Santano, R. A. González Polo, J. M. Bravo-San Pedro, R. Gómez-Sánchez, I. Lastres-Becker, M. A. OrtizOrtiz, G. Soler, J. M. Morán, A. Cuadrado and J. M. Fuentes, Activation of apoptosis signal-regulating kinase 1 is a key factor in paraquat-induced cell death: Modulation by the Nrf2/Trx axis, Free Radical Biol. Med., 2010, 48, 1370-1381.

11 S. Yiin, C. Chern, J. Sheu and T. Lin, Cadmium-induced liver, heart, and spleen lipid peroxidation in rats and protection by selenium, Biol. Trace Elem. Res., 2000, 78, 219-230.

12 M. L. Circu and T. Y. Aw, Reactive oxygen species, cellular redox systems, and apoptosis, Free Radical Biol. Med., 2010, 48, 749-762.

13 S. T. Y. Yeh, H. R. Guo, Y. S. Su, H. J. Lin, C. C. Hou, H. M. Chen, M. C. Chang and Y. J. Wang, Protective effects of $\mathrm{N}$-acetylcysteine treatment post acute paraquat intoxication in rats and in human lung epithelial cells, Toxicology, 2006, 223, 181-190. 
14 M. Tieppo, M. Porawski, M. Salvador, A. J. Moreira, P. S. Collado, J. G. Gallego and N. P. Marroni, Croton cajucara BENTH. Leaf Extract Scavenges the Stable Free Radical DPPH and Protects Against Oxidative Stress Induced by Paraquat, Biol. Pharm. Bull., 2006, 29, 161-165.

15 K. Shirisha and M. Mastan, Andrographis Paniculata and its bioactive phytochemical constituent for oxidative damage: A systemic review, Pharmacophore, 2013, 4, 212-229.

16 K. Kannan and S. K. Jain, Oxidative stress and apoptosis, Pathophysiology, 2000, 7, 153-163.

17 O. H. Lowry, N. J. Rosebrough, A. L. Farr and R. J. Randall, Protein measurement with the Folin phenol reagent, J. Biol. Chem., 1951, 193, 265-275.

18 M. Matsubara, K. Yamagami, Y. Kitazawa, K. Kawamoto and T. Tanaka, Paraquat causes S-phase arrest of rat liver and lung cells in vivo, Arch. Toxicol., 1996, 70, 514-518.

19 Y. S. KIM, H. Jung, T. Zerin and H. Y. Song, Protein profiling of paraquat-exposed rat lungs following treatment with Acai (Euterpe oleracea Mart.) berry extract, Mol. Med. Rep., 2013, 7, 881-886.

20 M. Singh, V. Murthy and C. Ramassamy, Neuroprotective mechanisms of the standardized extract of Bacopa monniera in a paraquat/diquat-mediated acute toxicity, Neurochem. Int., 2013, 62, 530-539.

21 S. Mitra, N. Chakrabarti and A. Bhattacharyya, Differential regional expression patterns of $\alpha$-synuclein, TNF- $\alpha$, and IL$1 \beta$; and variable status of dopaminergic neurotoxicity in mouse brain after Paraquat treatment, J. Neuroinflammation, 2011, 8, 163.

22 K. Manna, U. Das, D. Das, S. B. Kesh, A. Khan, A. Chakraborty and S. Dey, Naringin inhibits gamma radiation-induced oxidative DNA damage and inflammation, by modulating p53 and NFKB signalling pathways in murine splenocytes, Free Radical Res., 2015, 49, 422-439.

23 T. Yamamoto, J. Lewis, J. Wataha, D. Dickinson, B. Singh, W. B. Bollag, E. Ueta, T. Osaki, M. Athar, G. Schuster and $\mathrm{S}$. Hsu, Roles of catalase and hydrogen peroxide in green tea polyphenol-induced chemopreventive effects, $J$. Pharmacol. Exp. Ther., 2004, 308, 317-323.

24 A. J. Beige and S. D. Aust, Microsomal lipid-peroxidation, Methods Enzymol., 1978, 52, 302-310.

25 I. Yumoto, D. Ichihashi, H. Iwata, A. Istokovics, N. Ichise, H. Matsuyama, H. Okuyama and K. Kawasaki, Purification and characterization of a catalase from the facultatively psychrophilic bacterium Vibrio rumoiensis $\mathrm{S}-1(\mathrm{~T})$ exhibiting high catalase activity, J. Bacteriol., 2000, 182, 1903-1909.

26 S. Marklund and G. Marklund, Involvement of the superoxide anion radical in the autoxidation of pyrogallol and a convenient assay for superoxide dismutase, Eur. J. Biochem., 1974, 47, 469-474.

27 M. S. Moron, J. W. Depierre and B. Mannervik, Levels of glutathione, glutathione reductase and glutathione Stransferase activities in rat lungs and liver, Biochim. Biophys. Acta, 1979, 582, 67-78.

28 J. M. Hevel, K. A. White and M. A. Marletta, Purification of the inducible murine macrophage nitric oxide synthase, $J$. Biol. Chem., 1991, 266, 22789-22791.
29 N. Ismail, M. Ismail, S. F. Fathy, S. N. A. Musa, M. U. Imam, J. B. Foo and S. Iqbal, Neuroprotective effects of germinated brown rice against hydrogen peroxide induced cell death in human SH-SY5Y cells, Int. J. Mol. Sci., 2012, 13, 9692-9708.

30 C. J. Hsiao, S. H. Hsiao, W. L. Chen, J. H. Guh, G. Hsiao, Y. J. Chan, T. H. Lee and C. L. Chung, Pycnidione, a fungus-derived agent, induces cell cycle arrest and apoptosis in A549 human lung cancer cells, Chem.-Biol. Interact., 2012, 197, 23-30.

31 S. C. Cowley, E. Hamilton, J. A. Frelinger, J. Su, J. Forman and K. L. Elkins, $\mathrm{CD} 4^{-} \mathrm{CD}^{-} \mathrm{T}$ cells control intracellular bacterial infections both in vitro and in vivo, J. Exp. Med., 2005, 202, 309-319.

32 S. K. Sandur, H. Ichikawa, G. Sethi, K. S. Ahn and B. B. Aggarwal, Suppresses NF-kB Activation and NF-кBregulated gene products through modulation of p65 and I $\kappa \mathrm{Ba}$ kinase activation, leading to potentiation of apoptosis induced by cytokine and chemotherapeutic agents, J. Biol. Chem., 2006, 281, 17023-17033.

33 S. B. Kesh, K. Sikder, K. Manna, D. K. Das, A. Khan, N. Das and S. Dey, Promising role of ferulic acid, atorvastatin and their combination in ameliorating high fat diet-induced stress in mice, Life Sci., 2013, 92, 938-949.

34 A. Aiello, D. Delia, M. G. Borrello, D. Biassoni, R. Giardini, E. Fontanella, F. Pezzella, K. Pulford, M. Pierotti and G. D. Porta, Flow cytometric detection of the mitochondrial BCL-2 protein in normal and neoplastic human lymphoid cells, Cytometry, 1992, 13, 502-509.

35 D. A. Basketter, J. N. Bremmer, M. E. Kammuller, T. Kawabata, I. Kimber, S. E. Loveless, S. Magda, T. H. M. Pal, D. A. Stringer and H. W. Vohr, The identification of chemicals with sensitizing or immunosuppressive properties in routine toxicology, Food Chem. Toxicol., 1992, 32, 289-296.

36 M. S. Chohan, M. Tahir, K. P. Lone, W. Sami and B. Munir, Paraquat induced hepatotoxicity in albino mice, Pak. J. Zool., 2010, 42, 69-73.

37 M. Tomita, T. Okuyama, H. Katsuyama, Y. Miura, Y. Nishimura, K. Hidaka, T. Otsuki and T. Ishikawa, Mouse model of paraquat-poisoned lungs and its gene expression profile, Toxicology, 2007, 231, 200-209.

38 F. E. Harrison, J. L. Best, M. E. Meredith, C. R. Gamlin, D. B. Borza and J. M. May, Increased expression of SVCT2 in a new mouse model raises ascorbic acid in tissues and protects against paraquat-induced oxidative damage in lung, PLoS One, 2012, 7, e35623.

39 M. Shibata, F. Hakuno, D. Yamanaka, H. Okajima, T. Fukushima, T. Hasegawa, T. Ogata, Y. Toyoshima, K. Chida, K. Kimura, H. Sakoda, A. Takenaka, T. Asano and S. Takahashi, Paraquat-induced oxidative stress represses phosphatidylinositol 3-kinase activities leading to impaired glucose uptake in 3T3-L1 adipocytes, J. Biol. Chem., 2010, 285, 20915-20925.

40 P. R. Castello, D. A. Drechsel and M. Patel, Mitochondria are a major source of paraquat-induced reactive oxygen species production in the brain, J. Biol. Chem., 2007, 282, 1418614193. 
41 E. Eruslanov and S. Kusmartsev, Identification of ROS using oxidized DCFDA and flow-cytometry, advanced protocols in oxidative stress II, Methods Mol. Biol., 2010, 594, 57-72.

42 Y. Lu, B. Huang and Y. Huang, Reactive oxygen species formation and apoptosis in human peripheral blood mononuclear cell induced by $900 \mathrm{MHz}$ mobile phone radiation, Oxid. Med. Cell. Longevity, 2012, 2012, 740280.

43 C. Dezfulian, N. Raat, S. Shiva and M. T. Gladwin, Role of the anion nitrite in ischemia-reperfusion cytoprotection and therapeutics, Cardiovasc. Res., 2007, 75, 327-338.

44 E. E. V. Faassen, S. Bahrami, M. Feelisch, N. Hogg, M. Kelm, D. B. K. Shapiro, A. V. Kozlov, H. Li, J. O. Lundberg, R. Mason, H. Nohl, T. Rassaf, A. Samouilov, A. S. Schwok, S. Shiva, A. F. Vanin, E. Weitzberg, J. Zweier and M. T. Gladwin, Nitrite as regulator of hypoxic signaling in mammalian physiology, Med. Res. Rev., 2009, 29, 683-741.

45 J. A. Corbett, R. G. Tilton, K. Chang, K. S. Hasan, Y. Ido, J. L. Wang, M. A. Sweetland, J. R. Lancaster, J. R. Williamson and M. L. McDaniel, Aminoguanidine, a Novel Inhibitor of Nitric Oxide Formation, Prevents Diabetic Vascular Dysfunction, Diabetes, 1992, 41, 552-556.

46 H. I. Berisha, H. Pakbaz, A. Absood and S. I. Said, Nitric oxide as a mediator of oxidant lung injury due to paraquat, Proc. Natl. Acad. Sci. U. S. A., 1994, 91, 7445-7449.

47 P. Kesarwani, A. K. Murali, A. A. Al-Khami and S. Mehrotra, Redox regulation of T-cell function: From molecular mechanisms to significance in human health and disease, Antioxid. Redox Signaling, 2013, 18, 1497-1534.

48 S. Gao, Y. Wang, P. Zhang, Y. Dong and B. Li, Subacute Oral Exposure to Dibromoacetic Acid Induced Immunotoxicity and Apoptosis in the Spleen and Thymus of the mice, Toxicol. Sci., 2008, 105, 331-341.
49 K. B. Wee, U. Surana and B. D. Aguda, Oscillations of the p53-Akt Network: Implications on Cell Survival and Death, PLoS One, 2009, 4, e4407.

50 V. Rincheval, M. Bergeaud, L. Mathieu, J. Leroy, A. Guillaume, B. Mignotte, N. L. Floch and J. Vayssière, Differential effects of $\mathrm{Bcl}-2$ and caspases on mitochondrial permeabilization during endogenous or exogenous reactive oxygen species-induced cell death, Cell Biol. Toxicol., 2012, 28, 239-253.

51 Y. J. Jang, J. H. Won, M. J. Back, Z. Fu, J. M. Jang, H. C. Ha, S. B. Hong, M. Chang and D. K. Kim, Paraquat induces apoptosis through a mitochondria-dependent pathway in RAW264.7 Cells, Biomol. Ther., 2015, 23, 407-413.

52 L. K. Sharma, H. Fang, J. Liu, R. Vartak, J. Deng and Y. Bai, Mitochondrial respiratory complex I dysfunction promotes tumorigenesis through ROS alteration and AKT activation, Hum. Mol. Genet., 2011, 20, 4605-4616.

53 N. Itoh, S. Semba, M. Ito, H. Takeda, S. Kawata and M. Yamakawa, Phosphorylation of Akt/PKB Is Required for Suppression of Cancer Cell Apoptosis and Tumor Progression in Human Colorectal Carcinoma, Cancer, 2002, 94, 3127-3134.

54 X. Wang, F. Luo and H. Zhao, Paraquat-Induced Reactive Oxygen Species Inhibit Neutrophil Apoptosis via a p38 MAPK/NF-kB-IL-6/TNF-a Positive-Feedback Circuit, PLoS One, 2014, 4, e4407.

55 D. Tan, Y. Wang, B. Bai, X. Yang and J. Han, Betanin attenuates oxidative stress and inflammatory reaction in kidney of paraquat-treated rat, Food Chem. Toxicol., 2015, 78, 141-146.

56 K. Amirshahrokhi, Paraquat-induced pulmonary injury in mice, Int. J. Immunopharmacol., 2013, 17, 210-215. 